\title{
EXPERIENCIA DE VIVIR CON EL VIH / SIDA EN UN PAÍS LATINO: UN ANÁLISIS CUALITATIVO
}

\author{
María Isabel Peñarrieta de Córdova, PhD. , Ana María Rivera, Mg., \\ Socorro Piñones Martínez, Mg., Luz María Quintero Valle, Mg
}

Facultad de Enfermería Tampico Universidad Autónoma de Tamaulipas M éxico

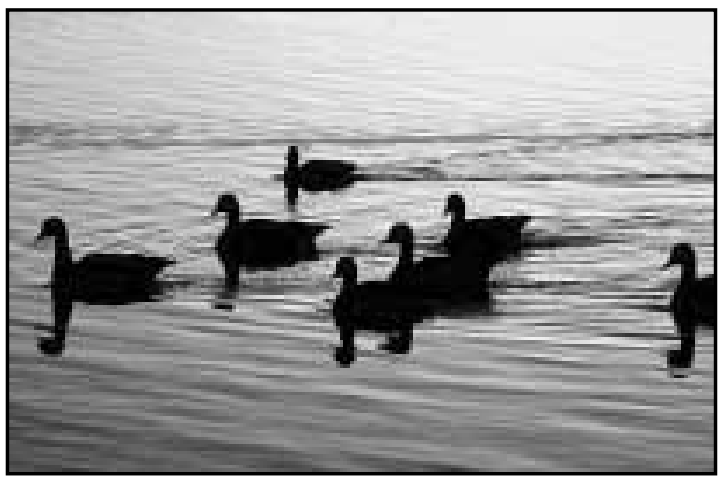

EXPERIENCE OF LIVING WITH AIDS IN A LATIN COUNTRY: A QUALITATIVE ANALYSIS

\section{SUMMARY}

7 he present article shows the results of a study made between March and April 2005.

The objective of this study was not only to analyze the experiences of living with HIV / AIDS, but also its meaning and the perspective of people who live with it in México.

The methodology used was qualitative by means of deep interviews to people who live with VIH and also belong to the Association of people who live with VIH in the city of TampicoTamaulipas- México.

Twenty eight deep interviews were recorded, rewritten and recodified using the Atlas version 4 programme. The results were grouped in 8 categories.

The results indicated that people who live with HIV/ AIDS present numerous problems and necessities. Similar results have been shown in Latin America. One of the major problem for people living with IHV / AIDS is the self stigma, external stigma and discrimination (occupational and from health workers) which are the cause of fear, loneliness and depression
Key words: HIV/ AIDS, Qualitative research, experiences of living with HIV/AIDS, stigma, discrimination

\section{RESUMEN}

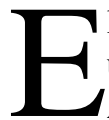
1 presente articulo presenta los resultados de un estudio realizado entre Marzo - 2004 y Abril 2005, cuyo objetivo fue analizar las experiencias de vivir con el VIH /SIDA, su significado y perspectivas de las personas que viven con esta enfermedad en México. La metodología fue cualitativa a través de la aplicación de entrevistas en profundidad a personas que viven con VIH que pertenecen a la Asociación de personas que viven con VIH en la ciudad de Tampico - Tamaulipas México. Se aplicaron 28 entrevistas en profundidad, siendo grabadas, transcritas y recodificadas utilizando el programa Atlas versión 4. Los resultados fueron agrupados en 8 categorías.

Los resultados indican que las personas que viven con VIH /SIDA presentan múltiples problemas y necesidades, resultados similares a otros estudios en Latinoamérica. Uno de los problemas de mayor impacto en las personas que viven con el VIH / SIDA es el, estigma interno, estigma externo y discriminación ( laboral y del personal de salud) originando sentimientos de temor, soledad y depresión.

PALABRAS CLAVES: VIH / SIDA, Investigación cualitativa, experiencia de vivir con VIH / SIDA,

\section{INTRODUCCIÓN}

El abordaje a la epidemia del VIH / SIDA esta teniendo un cambio de énfasis en su planteamiento, considerándose como prioritario la prevención positiva, esto es, centrado en las personas que viven con VIH / SIDA ( PVVS). Se consideran tres razones principales para justificar un abordaje 
de prevención positiva ( centrada en las PVVS): primera, una persona positiva esta involucrada en cada caso de VIH trasmitido; segundo, las personas que viven con el VIH tienen derecho de vivir bien con el VIH y tercero, la prevención del VIH, tratamiento, cuidados y soporte están interrelacionados, esto es que existe una relación Prevención tratamiento - Cuidados (ALLIANCE.,2003). Esta relación refuerza la racionalidad de intervenciones de prevención en PVVS. Por ejemplo, las PVVS necesitan evaluación médica y sico - social y también apoyo para fortalecer sus habilidades para desarrollar y mantener un comportamiento seguro. Esta experiencia ha demostrado ser satisfactoria en países como: Tailandia, Combodia, Uganda ( ALLIANCE,2002).

Por consiguiente, se hace necesario un mejor entendimiento de la experiencia de la enfermedad en esta población. El como las personas responden al tratamiento y aun sus síntomas se ha demostrado que es resultado de como ellos conceptualizan y experimentan la enfermedad (Katie E. Mosack \& col., 2005). Consecuentemente, evaluar la experiencia de vivir con el VIH /SIDA emerge como un elemento crítico en el proceso de atención a las personas viviendo con la enfermedad, conociendo mejor sus percepciones, dificultades en su manejo y cuidados y sus expectativas frente al tratamiento.

Los estudios realizados hasta el momento en Latino América muestran que la experiencia de vivir con el VIH / SIDA es heterogéneo, dependiendo del estrato económico, sexo y orientación sexual (Vàzquez Enid, 2002)

Personas con ingresos económicos bajos y consumidores de drogas enfrentan aun mayores retos. Por ejemplo, muchos son intermitentemente o crónicamente vagabundos. Esta situación conlleva a consecuencias de mayor deterioro. Adherirse a un régimen de tratamiento estricto y afrontar los efectos secundarios ( ejemplo: la diarrea) es difícil, aun cuando uno tiene un hogar; vivir en un ambiente sin estabilidad, la adherencia podría ser imposible . Por razones económicas, algunos tienen que vivir con amigos, miembros de la familia o parientes. En esos casos, ellos están en riesgo de ser rechazados si es conocido su status sero positivo (Katie E. Mosack \& col., 2005).
Situación similar presentan las personas que viven con VIH /SIDA con ingresos económicos bajos en países en vías de desarrollo como Latino América. Que aun sin ser drogo dependientes, sufren las consecuencias de estigma y discriminación, que en muchos casos viven una multidiscriminacion cuando se trata de hombres que tienen sexo con otros hombres, y mujeres (Vàzquez Enid, 2002; Kendall Tamil,Perez Vazquez Hilda,2004)

El informe del proyecto "Mo Kexteya" ( Instituto Nacional de Salud Publica de México, 2004), reporta que el estigma y discriminación relacionados con VIH en México ha incluido la negación de tratamiento a personas que viven con VIH, tratamientos inadecuados o inapropiados, la negativa a contratar o despidos injustificados, falta de confidencialidad y la indiferencia. También ha incluido violencia e incluso la muerte de personas que vivían con VIH o que se sospechaba que estaban infectadas. Los hombres gay y hombres que tienen sexo con otros hombres ( $\mathrm{HSH}$ ), grupos mayormente asociados con el SIDA en México, han sido blanco de odio y desdén por mucho tiempo; muchos se ven forzados a vivir una doble vida, ocultando su orientación sexual.

1. En este mismo estudio se identifica el estigma interno entre personas que viven con VIH/SIDA, refiriéndose a él como al estigma percibido o a las manifestaciones internas de un estigma aceptado o de percepciones sociales negativas transformadas en miedo, ansiedad o daño (algunas veces referido como estigma internalizado). El estigma interno puede manifestarse de varias formas: niveles profundos de auto denigración o reacciones a un nivel más superficial de vergüenza, acusación o culpa. Similares resultados son referidos también por otros autores (ONUSIDA, 2002; Shriver, Everett C, Morin SF, 2000 )

No se cuenta aun con suficientes estudios en Latino América sobre la experiencia de vivir con VIH / SIDA, y con el estigma y discriminación, de que manera se enfrentan a ello y como esta impactando su vida y la de su familia. Se espera que los resultados del presente estudio permita una mejor comprensión de esta realidad y así direccionar políticas y programas de atención más efectivos para este grupo de personas 


\section{METODOLOGÍA}

Diseño de investigación::Es un estudio descriptivo cualitativo tuvo como objetivo responder a las preguntas: $i$ que significa vivir con VIH / SIDA en un país latino?, como viven esta experiencia ?. Este estudio es la primera fase exploratoria de un estudio sobre prevención del VIH / SIDA en adolescentes en condiciones de pobreza, donde la participación de las personas que viven con VIH / SIDA es un componente importante en la intervención educativa.

Lugar y población: El estudio se realizo en la ciudad de Tampico - Tamaulipas, México. Estado ubicado en la frontera con Estados Unidos, por lo que el movimiento migratorio es importante, aunado a que la ciudad de Tampico es un puerto internacional.

La población de estudio fueron las personas viviendo con VIH / SIDA ( PVVS) que pertenecen a la Asociación de PVVS de Tampico : Frente Nacional de Personas que viven con VIH ( FRENPAVIH ) Tamaulipas - México. Esta asociación esta conformada por 150 miembros, de los cuales asisten a sus reuniones semanales en promedio 30 personas. En total se entrevistaron a 28 personas, usando el criterio de saturación en muestras cualitativas.

Métodos: El estudio utilizo entrevistas en profundidad con la finalidad de conocer sus experiencias viviendo con el VIH / SIDA, sus creencias, expectativas en su vida. También se incluyo su percepción sobre la atención brindada por el servicio de salud (Shriver MD, Everett C, Morin SF, 2000)

Instrumento: El equipo de investigación desarrollo una guía de preguntas con una descripción detallada para cada pregunta para garantizar consistencia en el momento del desarrollo de la entrevista. Este instrumento fue analizado por cada entrevistador garantizando así el entendimiento de lo que se buscaba en cada pregunta.

EL instrumento estuvo basado en preguntas que exploraban las siguientes áreas:

- El contexto socioeconómico de su familia de origen y su familia ò red de apoyo personal actual

- Su percepción y vivencia de la epidemia del $\mathrm{VIH}$
- La historia de consumo de droga: inicio, tipo de drogas, frecuencia, etc.

- La historia sexual incluyendo: con quien se inicio, a que edad, posibles experiencias de abuso sexual, el proceso de desarrollo de su identidad sexual y su orientación erótica, conducta sexual especifica, número de parejas sexuales, tipo de vinculación afectiva con ellas, experiencias intercambiando sexo por dinero ò por drogas o pagando personas que ejercen la prostituciòn. Descripción de un día regular en su vida desde que se despierta, descripción de una semana regular en su vida.

- Experiencia laboral, educación y demás datos demográficos. ( la edad)

- Su vida viviendo con el virus: experiencia con la prueba de VIH, con el resultado positivo, reacciones de la familia, de la pareja, de los amigos, asistencia psicológica y médica recibida, tratamiento antiretroviral, fluctuaciones en los niveles de carga viral, número de CD4, hospitalizaciones, etc.

- El futuro: expectativas de vida, a nivel afectivo, laboral, de autorrealización, etc.

Recolección de datos: Los participantes fueron invitados a participar en el estudio indicándoles que era totalmente anónimo y confidencial. Los criterios de inclusión al estudio fueron: que sean PVVS y estén en condiciones mentales de participar en la entrevista. Esta selección se realizo durante las reuniones que realizaba la asociación una vez por semana, invitando a participar al estudio a aquellos que recién llegaban a la reunión. Una vez aceptada la persona a participar, se acordaba la hora de la entrevista.

Las entrevistas se realizaron en un aula de la Universidad previamente preparada para mantener la individualidad de la entrevista. A cada participante se le invito un refrigerio durante la entrevista y se le pago sus pasajes. Las entrevistas se realizaron acorde a la hora y fecha propuesta por el entrevistado, de Marzo a Agosto del 2004.

Antes de iniciar la entrevista, se corroboro su aceptación voluntaria de participar en el estudio y su permiso para grabar la entrevista. Cada entrevista fue grabada y posteriormente codificada con un número para mantener el anonimato del infor- 
mante. La recolección de datos continuó hasta que no aparecieran nuevos datos en las transcripciones.

\section{ANÁLISIS DE LOS DATOS:}

Las entrevistas fueron transcritas por personal entrenado para realizar esta tarea, garantizando que se realice la trascripción de manera exacta como se registra en la entrevista.

Los datos fueron analizados utilizando técnicas cualitativas descriptivas para identificar categorías y temas de la descripción de los datos. Se utilizó métodos de análisis, síntesis, teorización y recontextualización (Peñarrieta Isabel, 2005). Los investigadores realizaron múltiples lecturas de las entrevistas a fin de comprender la integralidad de los datos, esto es la experiencia de vivir con el VIH / SIDA. Se utilizó el Programa ATLAS versión 4.0 para realizar la codificación de las entrevistas y posteriormente la agrupación en categorías e identificación de patrones. Para asegurar la validez de los resultados, los investigadores leyeron las transcripciones, revisaron las diferentes etapas del análisis de los datos, discutieron los diferentes puntos de vista hasta alcanzar un consenso en el significado y confirmación de los resultados. Se realizaron las codificaciones iniciales por parejas y luego se contrastaron con las identificadas por el resto de los investigadores. Posteriormente se mostraron los resultados a las personas que fueron entrevistadas para asegurar que se había dado el significado expresado en las entrevistas.

\section{RESULTADOS:}

Las características de la población estudiada son las siguientes: De las 28 entrevistas 21 se encuentras sin empleo estable o no tienen empleo, 17 dependen económicamente de sus familias, el 95\% solo han alcanzado estudios de nivel primario, aproximadamente el $50 \%$ refieren haberse salido de sus casas a temprana edad (12-15 años de edad ), 24 viven actualmente con su familia, 12 han tenido la experiencia migratoria a USA $\mathrm{u}$ otros estados de México, 7 son heterosexuales hombres, 8 heterosexual "mujer", 2 bisexuales hombres y 11 homosexuales. $99 \%$ han consumido drogas y alcohol, $8 \%$ drogas inyectables y $8 \%$ consumen actualmente drogas.

La experiencia de vivir con VIH / SIDA es descrito en 8 categorías, cada uno con sus temas res- pectivos : 1) sentimientos, 2) Interacción proveedor - Usuario, 3) Adherencia al tratamiento, 4) Estigma y Discriminación, 5) Homofobia, 6) Comportamiento sexual, 7) Rol de la familia y 8) expectativas del futuro. Para efectos de la publicación del presente artículo, se han priorizado la descripción del tema sobre estigma y discriminación

En esta categoría se identificaron tres temas: Estigma interno, Estigma externo, Discriminación (laboral y de la atención médica)

Estigma interno: Las entrevistas muestran en la gran mayoría de ellos un fuerte estigma hacia ellos mismos, traducido por un gran temor de contagiar a su familia o compañeros de trabajo. Llevándolos en algunos casos a abondanar el trabajo: “ aaayyy! pues, es difícil si últimamente por mi edad no he encontrado trabajo o sea de albañil ya no quiero. Yo se que si voy y pido trabajo de albañil lo encuentro, pos por que podía primeramente contagiar a los compañeros por que con el pico y la pala se hacen ampollas ee.. se puede cortar con la hoja de la, de la toluacha, herramientas que utilizamos entonces he querido alejarme de esos peligros aunque ahora ya descubro que no es peligroso "

En otros casos a realizar acciones de higiene de manera exagerada: “y aquí estas y aquí te vas a quedar, no me voy a sentir a gusto, es tu casa si tu te vas se desintegra la familia, por que yo, me dijo mi mujer si tu te vas yo me voy, aunque si... lo que ya paso ya ni modo no se te va reprochar nada pero así vamos ir navegando todos en el mismo barco, les digo bueno yo nada mas les quiero pedir un favor, quiero tener cloro en el baño de abajo, cloro en el baño de arriba mis botellas, cloro aquí, no quiero que nadie se me acueste en mi cama, no quiero que nadie me limpie mi cuarto yo soy él que voy hacer todo el aseo de mi recamara, si? Voy apartar mis platos, voy apartar mis platos hondos, extendidos, cucharas todo, pero es que estas mal, eso no es así, bueno no es así pero a veces yo puedo traer una pelada, no se, para que los voy exponer y si yo me siento a gusto por favor déjenme, déjenme si es que quieren que me quede $\mathrm{y}$ hasta la fecha vamos"

Así mismo, este estigma interno se ve reflejado por el sentimiento de culpa expresado en los entrevistados, consideran que tienen el VIH / SIDA por su mal comportamiento y que están pagando las 
consecuencias de sus malos actos: “..por eso me sentí mal, cuando supe yo de mi problema.." ".todo mal acto lleva una mala consecuencia.."

“.. es el precio que estoy pagando todo lo que he hecho...."

Estigma externo: El estigma externo se caracteriza principalmente por culpar a las personas que viven con VIH / SIDA, expresiones como: "mi mamá me dijo: es que tú te lo buscaste"son frecuentes en las entrevistas. Por otro lado, también se expresa este estigma con el abandono familiar como es este caso: "cuando yo salí de ahí del seguro, que me dieron de alta, regresé a la casa, y ya no estaba mi señora ni el niño, se lo había llevado, ya, el niño tiene cuatro años, y el niño ya, tiene dos años que no lo veo, que, que pasó ¿Cuando tu saliste del seguro, fue por el accidente o porque fue? porque ella se, se, el doctor le dijo que yo tenia VIH,"

Así mismo, el gran temor " a que se enteren los demás" por parte de la familia es también frecuente: "tu, si se llegan a enterar tu di que tienes Cáncer, le digo, ja!! Si supieras que el cáncer es peor le digo, mamá te juro que si me diagnosticaran cáncer te vas arrepentir de habérmelo dicho y me peleé con ella, o sea me molestó y es la que no, todavía como que no quiere que se entere la gente,"

Existe un gran temor a "contagiarse" recurriendo incluso a usar técnicas sin mayor razón como es la fumigación de la casa donde una persona con VIH / SIDA haya muerto: "ella me decía, de la gente de sus alrededores que era lo peor y que fueron y fumigaron la casa y nunca se me olvidará eso, eso, pero no es así, así no era, nos trataban de una manera muy fea muy cruel.mmmfff...

\section{Discriminación (de la atención médica y labo-}

ral): Las entrevistas revelan situaciones de discriminación para recibir atención medica, sobre todo cuando se trata de atención del parto "para salvar al niño, entonces ya me empecé a tomar el medicamento...." "porque no me querían operar, no me querían atender,..." , así como con el trato recibido por parte de los proveedores: "Después si, después si me cayó el peso, pero en el momento no, no la sentí impactante, después si sentí, el peso por que ya empecé a tener problemas con el personal de salud ahí si, empecé a tener rechazo, que me regañaban ,que me señalaban, que me juzgaban, ahí si empecé a tener problemas.

En aspectos de discriminación laboral, se presentan en casos relacionados con el ejercito donde existe reglamentos internos para tratar a personas que viven con VIH / SIDA:

¿Estaba en mi cuarto solo, no? y estaba yo, llorando, porque luego, luego a mi, me incapacitaron, me mandaron a mi domicilio, tu te vas a tu domicilio y nada mas te vas a presentar a cobrar y ya, a que se te de un documento que avale que tu estas en domicilio.... y toda...y eso fue por el médico? por él medico, me empezaron a excluir, de exclusivo, o sea, excluir de la milicia, entonces ya ahorita a la milicia, no voy mas que a cobrar y a dejar un documento que me ampare, como militar, todavía, ósea que yo, me encuentro en mi domicilio, vea? y has averiguado si esto no te acarrea problemas laborales? hee, no, no me acarrea ningún problema laboral, es, de, es dentro del proceso que se lleva ahí adentro de la Armada, te empiezan a rebajar a domicilio, para que acumules ciertos días, si? de no laborar, entonces cuando tu acumulas ciertos días se abre un proceso, se te manda certificar médicamente y se te tramita la baja, la baja definitiva, entonces es lo que a mi me están haciendo, pero haga de cuenta que hay leyes, reglamentos que son internos.

Otro aspecto relacionado con el estigma y discriminación en personas que viven con VIH / SIDA, es la homofobia. Acentuándose esta cuando un hombre que tiene sexo con otro hombre es infectado con el VIH. La homofonía expresada en las entrevistas se refiere principalmente de los padres de los hombres que tienen sexo con otros hombres, tanto del padre como de la madre. Esta homofobia ha causado mucho sufrimiento durante la niñez de estas personas, he inclusive como se refiere en los datos demográficos ha sido razón para que estas personas salgan a muy temprana edad de sus casas. Estos son algunos testimonios:

"Me rechazó en aquellos años que duramos casi 30 años así de disgusto los dos vea! que no bien me quería porque yo era homosexual y más, se que no me quería porque él es demasiado hombre es demasiado varón vea! tuvo mujeres" 
“...eemmm... mire...mmm...(guarda silencio, y se quebranta un poco) lo que siempre me ha cargado así, en mi pensar, siempre mi padre, el siempre me hizo a un lado (silencio y llanto discreto), el siempre, el siempre, me hizo el me rechazo me hizo a un lado, a un lado, a un lado...y lo traigo... de ahorita ni de ayer, esto desde que viví toda mi vida lo traigo mmmfff... no, en el siempre me hizo a un lado, a un lado siempre... y ahorita que tengo esta edad digo pues... No, no, no era por ahí que me tratara de, de, esa, esa manera pero. mmmfff no, no o juzgo el ya murió pero no se porque me trataba de esa manera."

\section{DISCUSIÓN}

Los resultados del presente estudio, nos permite identificar varios aspectos de lo que es la experiencia de vivir con el VIH en un país latinoamericano, las cuales corroboran los resultados encontrados en otros estudios en contextos similares en otros países de Latinoamérica(Morse J, 1994). En el presente estudio, estos resultados representan a las personas que viven con VIH en condiciones económicas deficientes, donde la mayoría carece de un empleo estable y de contar con un seguro de atención a su salud. Estos dos aspectos aunado con la presencia del estigma y discriminación tienen un impacto muy importante en como se vive esta experiencia.

Es así, que los resultados del presente estudio muestran que una de las grandes dificultades a las cuales tiene que lidiar es el estigma y la discriminación, que como se ha presentado en los resultados este se experimenta tanto al interior de ellos mismos como en el contexto social. Aspecto que no es exclusivo en la zona de estudio, sino que es presentado también en el país como uno de los mayores problemas que se tiene que abordar al enfrentar el VIH/SIDA (UNAIDS, 2003). Situación que compromete a la sociedad en su conjunto, incluyendo a la familia y a las instituciones de salud.

El estigma interno expresado como el temor a contagiar, conlleva a un aislamiento y por consiguiente a una pérdida en utilizar o buscar el soporte de red social y en algunos casos la pérdida laboral con las consiguientes pérdidas económicas. Así mismo, los efectos perjudiciales al exagerar los auto- cuidados en la higiene, como es el uso del cloro que podría traer efectos secundarios para su salud; los sentimientos de culpa con la consiguiente disminución de su autoestima y en sus auto cuidados.

El estigma externo manifestado como el temor a lo que digan los demás y la culpabilizacion hacia las personas que fueron infectadas con el virus VIH por "su mal comportamiento" no solo refuerza el estigma interno ya existente, sino que contribuye a que las actividades de prevención del VIH/SIDA no sea tratado como debiera, por ejemplo en la percepción de riesgo por la sociedad en general, considerando que sólo pueden estar en riesgo determinados grupos de "mal comportamiento" no tomando así medidas de prevención frente a la enfermedad. Es también importante considerar la homofobia como aspecto importante que podría explicar la existencia previa como facilitador para acentuar el estigma presente frente al VIH / SIDA (Mayorga Ruben, 2003).

Por otro lado, la discriminación, esto es los actos de rechazo hacia las personas que viven con el VIH como respuesta al estigma ya existente se encuentran aún presentes. Esta discriminación laboral y en la negación a una atención medica por parte del sistema de salud tiene graves consecuencias en la calidad de vida de este grupo. Se acentúa mucho mas cuando la discriminación a la atención es hacia las mujeres embarazadas al retardar una atención oportuna en el momento del parto, repercutiendo no sólo hacia la madre sino también en su hijo / a.

Uno de los principales aspectos a considerar en la presencia de este estigma y discriminación es la carencia de información a las PVVS sobre la enfermedad y cuidados a tener en cuenta viviendo con el VIH. La implementación de un Programa educativo básico sobre estos aspectos, no solo permitiría disminuir este estigma y mejorar el auto cuidado y por ende disminuir problemas de adherencia y de enfermedades oportunistas, sino que además estarían evitando reinfecciones y nuevas infecciones

Por otro lado, los resultados sugieren otro desafío importante en esta área que es la debilidad por parte de los proveedores de atención de la salud en su formación profesional para manejar estos temas 
y situaciones, aspectos de gran trascendencia para abordar esta epidemia (Seal DW, Ehrhardt AA., 2004)

\section{REFERENCIAS}

- ALliANCE. (2003 )Positive Prevention: Prevention Strategies for people with HIV / AIDS. Draft Background paper, June -

- Charles M. (1996)HIV / AIDS: Some issues related to ITS prevention and care. Health Millions. Jan - Feb; 2(1): 12-4

- Horizons Program / International HIV / AIDS ALLIANCE Greater Involvement of people with HIV in NGO service delivery (2002)Finding from a four country study . July

- Instituto Nacional de Salud Publica de México - Proyectos Políticas México (2004) Mo Kexteya Reducción del Estigma y Discriminación Relacionados con el VIH y el SIDA en México Diciembre.

- Katie E. Mosack, Maryann Abbott, Merrill Singer, Margaret R. Weeks, Lucy Rohena. (2005 ). If I didnt have HIV, Y`d be dead now: Illness Narratives of drugs Users Living with HIV / AIDS. Qualitative Health Research, 15 (5) :586 - 605.

- Kendall Tamil,Perez Vazquez Hilda (2004) Hablan las mujeres mexicanas VIH positivas. Colectivo Sol : 71-78.

- Mayorga Ruben (2003)Derechos humanos y movilizacion comunitaria. La respuesta social y cultural. En: Situación del VIH / SIDA en America Latina y el Caribe. Una revisión basada en el foro. Editor Fundación Mexicana para la Salus, SIDALAC, ONUSIDA, GCTH. Mexico.

- Morse J. (1994) Emerging from the date. The cognitive process of analysis in qualitative inquiry in Morse J. Ed. Crital Issues in Qualitative Research Method. Newbory Park. CA Sage.: $23-48$.

- ONUSIDA (2002 ). Marco conceptual y base para la acción: estigma y discriminación relacionado con el VIH / SIDA . Ginebra: ONUSIDA

- Peñarrieta I. (2005). Introducción a la Investigación Cualitativa.. Editores Textos Mexicanos. Mexico.pp 20-85.

- Seal DW, Ehrhardt AA. (2004) HIV - Prevention - related sexual promotion for heterosexual men in the United States: pirfalls and recommendation. Arch Sex Behav. 23 (3) $211-$ 22.

- Shriver MD, Everett C, Morin SF. (2000). Structural Intervention to encourage primary HIV prevention among people living with HIV. AIDS. 14 Suppl 1: S 57-62.

- UNAIDS. (2003) Report on the global HIV / AIDS epidemic.

- Vàzquez E. (2002) Impacto del VIH / SIDA en la calidad de vida. XIV Conferencia Internacional sobre el SIDA. Barcelona

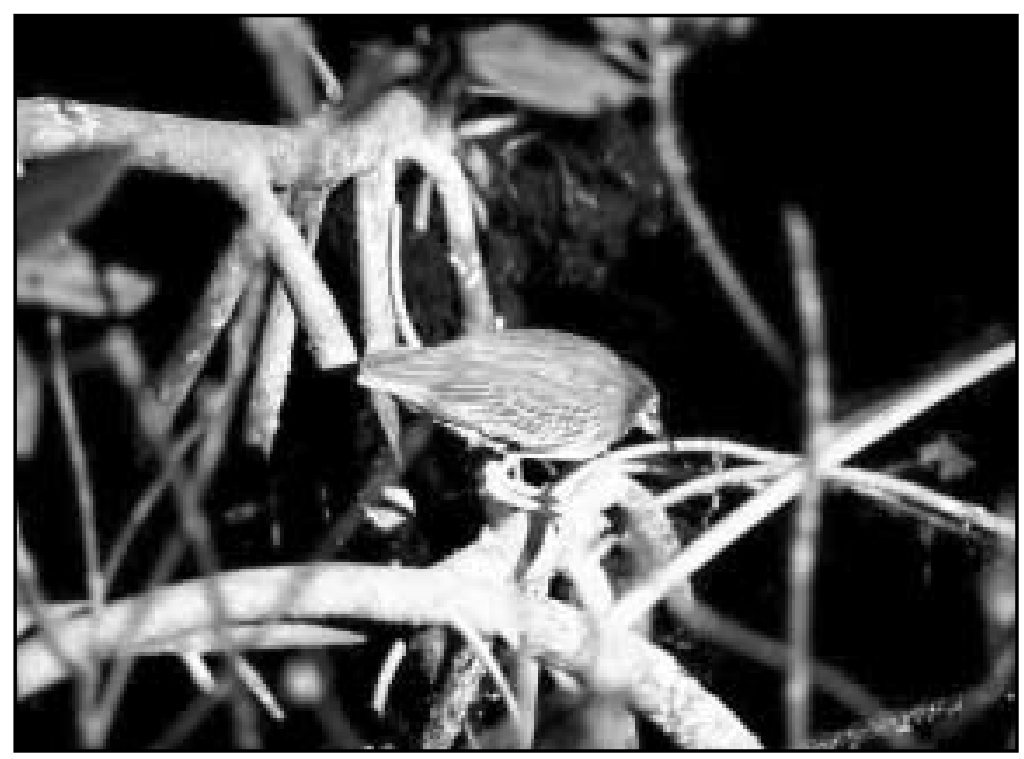

